\title{
New Medium for Pharmaceutical Grade Arthrospira
}

\author{
Amro A. Amara ${ }^{1}$ and Alexander Steinbüichel ${ }^{2}$ \\ ${ }^{1}$ Department of Protein Research, Genetic Engineering and Biotechnology Research Institute, (Mubarak) City for Scientific Research \\ and Technology Applications, Universities and Research Centre District, New Borg El-Arab, P.O. Box 21934, Alexandria, Egypt \\ ${ }^{2}$ Institut für Molekulare Mikrobiologie ünd Biotekhnologie, Westfälishen Wilhelms-Universität Münster, Corrensstraße 3, \\ 48149 Münster, Germany
}

Correspondence should be addressed to Amro A. Amara; amroamara@web.de

Received 29 May 2013; Revised 3 November 2013; Accepted 14 November 2013

Academic Editor: Gary Dykes

Copyright (C) 2013 A. A. Amara and A. Steinbüchel. This is an open access article distributed under the Creative Commons Attribution License, which permits unrestricted use, distribution, and reproduction in any medium, provided the original work is properly cited.

\begin{abstract}
The aim of this study is to produce a pharmaceutical grade single cell product of Arthrospira from a mixed culture. We have designed a medium derived from a combination between George's and Zarrouk's media. Our new medium has the ability to inhibit different forms of cyanobacterium and microalgae except the Chlorella. The medium and the cultivation conditions have been investigated to map the points where only Arthrospira could survive. For that, a mixed culture of pure Chlorella and Arthrospira ( 90:10) has been used to develop the best medium composition that can lead to the enrichment of the Arthrospira growth and the inhibition of the Chlorella growth. To enable better control and to study its growth, an 801 photobioreactor has been used. We have used high saline (2xA-St) medium which has been followed by in fermentor reducing its concentration to $1.5 \mathrm{x}$. The investigation proves that Chlorella has completely disappeared. A method and a new saline medium have been established using a photobioreactor for in fermentor production of single cell Arthrospira. Such method enables the production of pure pharmaceutical grade Arthrospira for medicinal and pharmaceutical applications or as a single cell protein.
\end{abstract}

\section{Introduction}

Using algae as a food and medicine is deeply rooted in the human history. In ancient Egypt and today, farmers used to collect floating algae on the surface of the water to feed their domestic birds. In a harsh environment when the land resources food become rare, alkaline lakes play a significant role as an alternative source. The alkaline lakes enable the growth of one of the few nontoxic cyanobacterial species, Arthrospira fusiformis [1]. Humans learned early how to use the Arthrospira as a food source. Seeing the migrant birds feed safely on Arthrospira, such as lesser flamingoes (Phoeniconaias minor Geoffroy), encourages such use. Kebeda (1997) reported that in Ethiopia, farmers and herdsmen living in areas close to the soda lakes make their cattle drink Arthrospira water about once a month and believe that it has therapeutic effects and compensates for some lack in dietary food [2].

The invention of the microscope enabled Turpin in 1827 to identify and describe Arthrospira as spiral cyanobacteria
[3]. Species of Arthrospira have been found in a variety of environments including soil, sand, marshes, brackish water, seawater, and freshwater [1, 4]. Rich (1931) has reported it as a dominant phytoplankton in a number of lakes in the Rift Valley of East Africa [5]. 113 years after its first microscopic identification, Arthrospira was reintroduced to the world by Dangeard (1940) from a sample collected by Mr. Cŕeach (a pharmacist) from a local market in Shad $[1,6]$. Arthrospira contains high levels of proteins (50-70\%), lipids (7-16\%), vitamins, and omega-3 fatty acid [7-9]. For economic production of Arthrospira, it is usually cultivated in open ponds, so the absorbed solar energy is used to fix inorganic carbon. Arthrospira is produced in quantities exceeding 3000 tons/year of dry material [10]. In a survey concerning its production, Shimamatsu (2004) highlighted that its contamination by other algal species is one of the main problems concerning its production in the open ponds [10]. The analysis of its natural habitat enabled Zarrouk (1966) to introduce his famous alkaline medium [11]. Moreover, scientists have observed that it has become the most 
dominant species in high salt content lakes (>30 g/l) [12]. For better understanding and growth control, closed tubular photobioreactors with working volumes ranging from 5 to 36,0001 were used for the production of different cyanobacteria including Arthrospira [13-18]. Arthrospira fusiformis (formerly Spirulina platensis) is the main microalgae which is produced commercially in large scale as food or as nutraceutical food and single cell protein [19]. Arthrospira can grow in extremoalkalophilic and halophilic habitat as well as in fresh water [1]. It is used in the diets of fish and poultry and even sold as a healthy food [8]. It has been utilized for the production of cyanocobalamin (B12), antioxidant pigments like $\beta$-carotene, tocopherols, and $\gamma$-linolenic acid $[7,8,20,21]$.

The deep blue color of phycocyanin and other extractable pigments including myxoxanthophyll and zeaxanthin have been widely used as naturally occurring colorants for food additive purposes [22-25]. Phycocyanin and the Arthrospira's exopolysaccharide have anticancer, antioxidant, antiviral, and anti-inflammatory activities and can be used as a tonic agent for the immune system $[26,27]$. Producers used to increase alkalinity to reduce the number of algal species [10]. Arthrospira uses sunlight and $\mathrm{CO}_{2}$ to grow (autotrophic) or organic compounds (auxotrophic) or both (autoauxotrophic). For economic production of Arthrospira, alkaline open ponds are usually used for large-scale production. However, the major problem in its biomass production is the contamination with other algae and cyanobacteria which reduce the final product quality [10]. Few studies reported that Arthrospira can resist high salinity and that it becomes dominant in part of the years in its natural habitat $[1,2,12]$. While alkaline open ponds mimic the Arthrospira natural habitat, we are suggesting that salinity could play a significant role in Arthrospira enrichment and that the rain/evaporation cycle on the lake and the lake's surrounding area lead to salt accumulation, which leads to enrichment of Arthrospira over other algal and cyanobacterial species. Salt stress has been studied with less attention in other Arthrospira-related subjects $[2,28,29]$.

In this study and for the first time, we introduce a simple strategy for single cell Arthrospira production in a photobioreactor using a new medium extracted from the nature and from the information in the literatures. We introduce two steps using the photobioreactor to eradicate Chlorella and to gain $100 \%$ pure Arthrospira.

\section{Material and Methods}

2.1. Chemical. All chemicals used were analytical grade and obtained from Sigma-Aldrich and Roth.

2.2. Cyanobacteria Strains. The extremoalkalophilic cyanobacteria strains used in this study were isolated from Lake Maryut, Alexandria, Egypt, and were identified using a light microscope as Arthrospira and Chorella. Arthrospira was identified by Sharaf et al. (2010) as A. fusiformis by sequencing and analysis of the PC-IGS regions in the gene of phycocyanin [26].

The A. fusiformis and Chlorella spp. strains were grown and cultivated routinely in Zarrouk's or George's media at room temperature $\left(20-25^{\circ} \mathrm{C}\right)$ in lab condition under lamp/sunlight [11].

\subsection{Media}

2.3.1. George's Medium. One liter of George's medium consists of peptone $1.00 \mathrm{~g}, \mathrm{KNO}_{3} 0.20 \mathrm{~g}, \mathrm{~K}_{2} \mathrm{HPO}_{4} 0.02 \mathrm{~g}, \mathrm{MgSO}_{4}$ $.7 \mathrm{H}_{2} \mathrm{O} 0.02 \mathrm{~g}$, and Ferric citrate $0.035 \mathrm{~g}$ [30].

2.3.2. Zarrouk's Medium [11]. One liter of Zarrouk's medium consists of (part A) $\mathrm{NaHCO}_{3} 16.80 \mathrm{~g}$ and $\mathrm{K}_{2} \mathrm{HPO}_{4} 0.50 \mathrm{~g}$; (part B) $\mathrm{NaNO}_{3} 2.50 \mathrm{~g}, \mathrm{~K}_{2} \mathrm{SO}_{4} 1.00 \mathrm{~g}, \mathrm{NaCl} 1.00 \mathrm{~g}, \mathrm{MgSO}_{4}$ $\cdot 7 \mathrm{H}_{2} \mathrm{O} 0.20 \mathrm{~g}$, EDTA- $\mathrm{Na}_{2} \cdot 2 \mathrm{H}_{2} \mathrm{O} 0.08 \mathrm{~g}, \mathrm{CaCl}_{2} \cdot 2 \mathrm{H}_{2} \mathrm{O} 0.04 \mathrm{~g}$, and $\mathrm{FeSO}_{4} \cdot 2 \mathrm{H}_{2} \mathrm{O} 0.01 \mathrm{~g}$; trace elements mixture A (part C $10 \mathrm{~mL} / \mathrm{l}$ ): $1.00 \mathrm{~mL}$, trace elements mixture $\mathrm{B}$ (part $\mathrm{D}$ $1.0 \mathrm{~mL} / \mathrm{l}): 1.00 \mathrm{~mL}$; part C mg/l: $\mathrm{H}_{3} \mathrm{BO}_{3} 2.86, \mathrm{MnCl}_{2} \cdot 4 \mathrm{H}_{2} \mathrm{O}$ $1.810 \mathrm{~g}, \mathrm{ZnSO}_{4} \cdot 7 \mathrm{H}_{2} \mathrm{O} 0.222 \mathrm{MoO}_{3} \cdot 0.015$, and $\mathrm{CuSO}_{4} \cdot 5 \mathrm{H}_{2} \mathrm{O}$ 0.074 (the used amount is $10 \mathrm{~mL} / \mathrm{l}$ ); part $\mathrm{D} \mathrm{mg} / \mathrm{l}: \mathrm{NH}_{4} \mathrm{VO}_{3}$ 22.9, $\mathrm{NiSO}_{4} \cdot 7 \mathrm{H}_{2} \mathrm{O} 47.8, \mathrm{NaWO}_{2} 17.9, \mathrm{Ti}_{2}\left(\mathrm{SO}_{4}\right)_{3} \cdot 6 \mathrm{H}_{2} \mathrm{O}$, and $\mathrm{Co}\left(\mathrm{NO}_{3}\right)_{2} \cdot 6 \mathrm{H}_{2} \mathrm{O} 4.4$ (the amount used was $1.0 \mathrm{~mL} / \mathrm{l}$ ) [11].

2.3.3. Amara and Steinbüchel (A-St) Medium 1x. One liter medium of A-St consists of (part A) $\mathrm{NaHCO}_{3} 9.214 \mathrm{~g}, \mathrm{NaCO}_{3}$ $7.143 \mathrm{~g}$, and $\mathrm{K}_{2} \mathrm{HPO}_{4} 0.5 \mathrm{~g}$; (part B) $\mathrm{NaNO}_{3} 1.5 \mathrm{~g}, \mathrm{~K}_{2} \mathrm{SO}_{4}$ $0.571 \mathrm{~g}, \mathrm{NaCl} 1 \mathrm{~g}, \mathrm{MgSO}_{4} \cdot 7 \mathrm{H}_{2} \mathrm{O} 0.2 \mathrm{~g}, \mathrm{CaCl}_{2} \cdot 2 \mathrm{H}_{2} \mathrm{O} 0.012 \mathrm{~g}$, $\mathrm{FeSO}_{4} \cdot 2 \mathrm{H}_{2} \mathrm{O} 0.01 \mathrm{~g}$, and EDTA- $\mathrm{Na}_{2} \cdot 2 \mathrm{H}_{2} \mathrm{O} 0.08$ g; (part C) ferric citrate $0.018 \mathrm{~g}$; (part D) peptone $0.1 \mathrm{~g}$; yeast extract $0.01 \mathrm{~g}$.

2.4. Photobioreactor. The photobioreactor used in this study was installed at the Institut für Molekulare Mikrobiologie ünd Biotekhnologie, Westfälishen Wilhelms-Universität, Münster, Germany, and has been previously described in detail by $\mathrm{Hai}$ et al. (2000) [16]. Its major features are as follows: it is made from helical Boresist DN80 glass tube $(14 \mathrm{~m})$ (Schott Glaswerke, Mainz, Germany) and is connected to a degassing chamber (8.0 l) (Figures $1(\mathrm{a})$ and $1(\mathrm{~b})$ ). The photobioreactor surface/volume (s/v) ratio is about $44 / \mathrm{m}$ (Figure 1). The top of the degassing chamber was closed with a stainless steel plate providing ports (Figure 1(b)). A sealed pump module connected to a two-blade propeller was installed in the bottom of the photobioreactor and supplied with Pt-100 temperature sensor and contained an outlet to release the cell for harvesting (Figures 1(a), 1(b)). Three supplied light panels were placed in the interspaces and on both longitudinal sides of the photobioreactor. Each light panel contained 10 Osram Nature Deluxe, U- or L- shaped tubes (Osram, Munich, Germany) for maximum photon flux. The light intensity of each panel could be varied by dimming (Figures 1(a), 1(b), and 1(c)). Lighting with photon flux of approximately $0,100,400$, and $600 \mu \mathrm{E} / \mathrm{m}^{2}$ xs was applied to the cultivation process. Sterility of gas inlet or outlet was maintained by the ceramic bacterial filter.

2.5. In Flask Cultivation. $250 \mathrm{~mL}$ flasks each contains $50 \mathrm{~mL}$ of Zarrouk's medium or George's medium were used for routine cultivation. When we used Zarrouk's medium, part A was autoclaved, while part B and the trace elements 


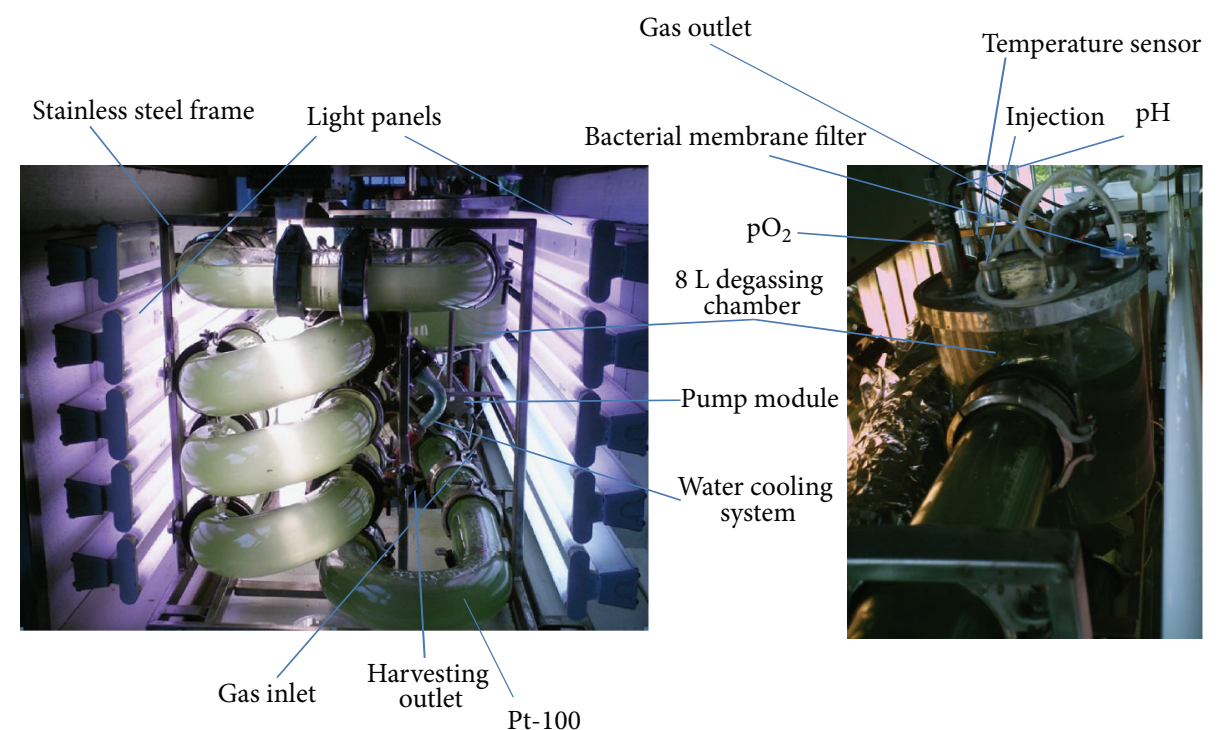

(a)

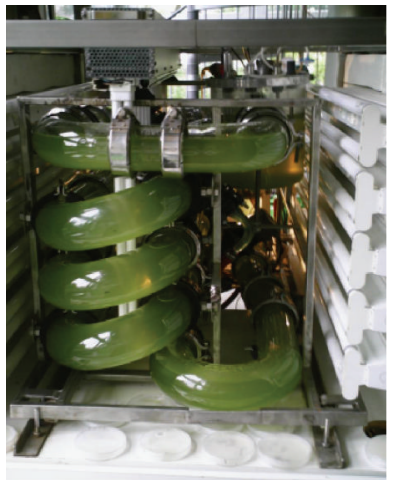

(c)

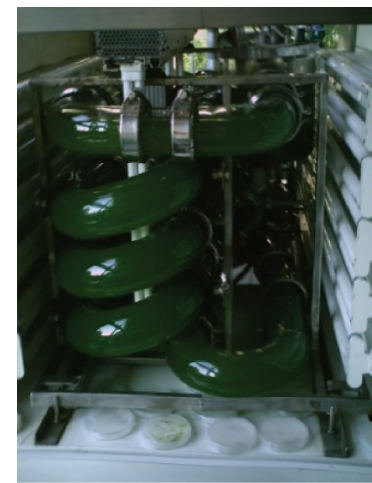

(d)

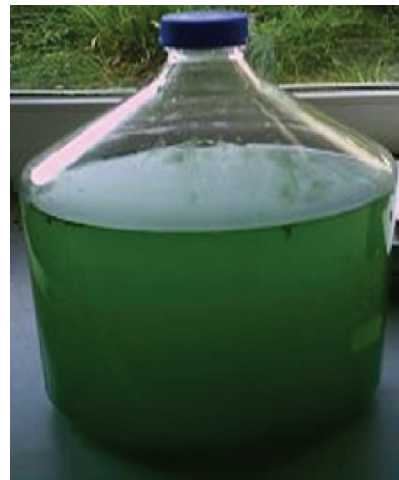

(e)

FIGURE 1: (a) Night profile of the photobioreactor showing the light system. (b) Degassing chamber and its stainless steel cover which contains different ports and growth mentoring probes (e.g., $\mathrm{pH}$ meter, $\mathrm{CO}_{2}$ and $\mathrm{O}_{2}$ electrodes, temperature sensor, and sample collection port). (c) Light growth of the Arthrospira after the medium dilution. (d) Heavy growth of the Arthrospira at the end of the cultivation process. (e) Static cultivation of Arthrospira using sun light only.

solutions A and B were sterilized separately using a bacterial membrane filter $(0.22 \mu \mathrm{m})$. For routine cultivation, light from a florescent lamp/sunlight and temperature ranging from 20 to $25^{\circ} \mathrm{C}$ under static condition were used.

2.6. In 201 Bottle Cultivation. 201 bottle was used to draw the $2 \mathrm{x}$ medium from the photobioreactor during the dilution process. The removed $2 \mathrm{x}$ medium was adjusted to $1.5 \mathrm{x}$ and the Arthrospira was allowed to grow (under static condition same as above) (Figure 1(e)).

\subsection{In Photobioreactor Medium Sterilization and Cultivation.} The entire photobioreactor, except light panels and motor, was sterilized after adding 691 of tap water containing part A from 2x A-St medium using model 6612-1 ED chamber autoclave (KSG Sterilization GmBH, Olching, Germany). Part B and part $\mathrm{C}$ were sterilized separately using sterile bacterial membrane filter $(0.22 \mu \mathrm{m})$. The total volume of the medium constituents has been made to 11 and added separately to the photobioreactor to achieve a total volume of 701 . Part 4 which contains the yeast extract/peptone was autoclaved using normal autoclave. The electrodes and the ceramic filters were sterilized separately.

2.8. Cultivation Condition. The photobioreactor enabled automatic control. The temperature was set to $30^{\circ} \mathrm{C}$ and was adjusted automatically. The stirrer speed (motor speed), the $\mathrm{pO}_{2}$, and the $\mathrm{pH}$ were monitored automatically. The parameters at the starting point were $\mathrm{pH} 9.34, \mathrm{pO}_{2} 80$, motor speed $0 \mathrm{rpm}$, temperature $26^{\circ} \mathrm{C}$, and $600 \mu \mathrm{E} / \mathrm{m}^{2}$ xs. Samples were taken regularly and whenever possible.

2.9. Cell Dry Weight (CDW). CDW was calculated by correlating weight to volume as $\mathrm{g} / \mathrm{L}$. Filter papers or gauze, or both, were used. The paper or gauze was weighed before being used and dried after filtration, and the weight correlated to the volume was used as CDW $\mathrm{g} / \mathrm{L}$. 


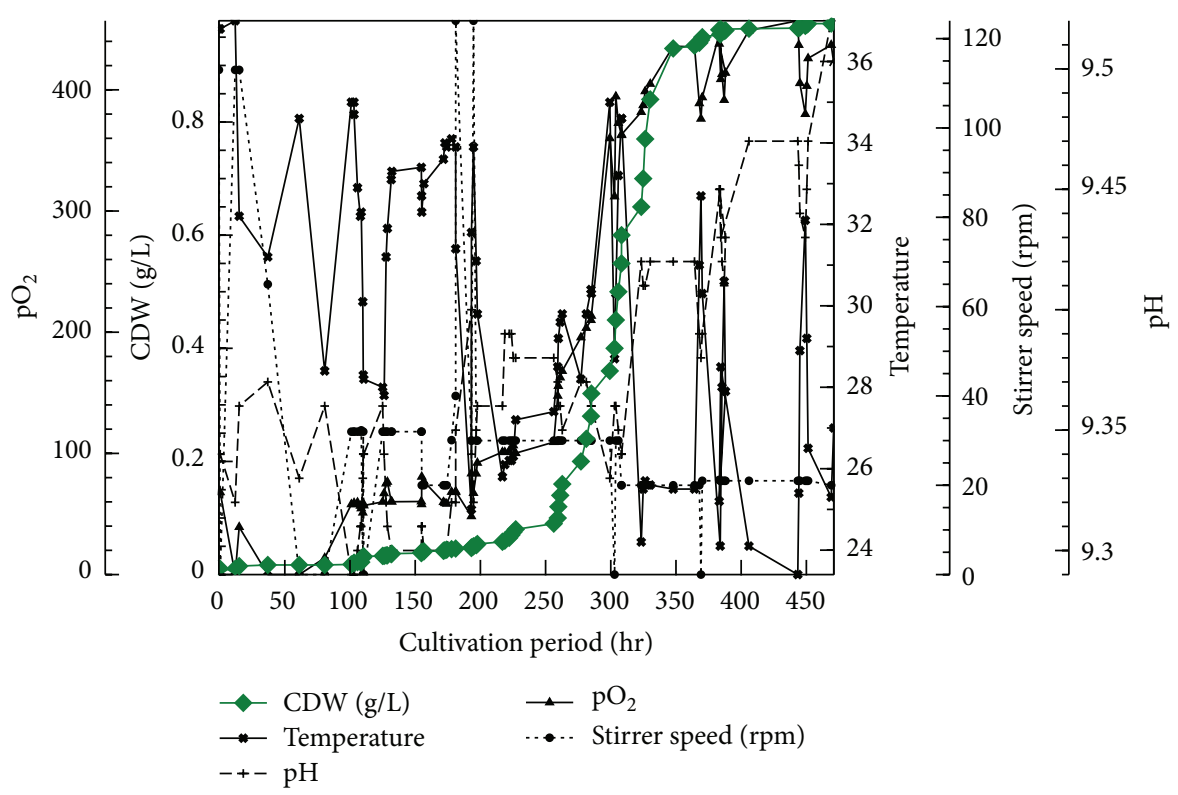

FIgURE 2: The overall cultivation process using photobioreactor. The heavy green line shows the CDW g/l.

2.10. Microscopic Examination. Samples were drawn from the photobioreactor regularly and whenever possible and were examined using light microscope.

2.11. Salinity and Media Composition Study. A comparison study was done between the different used media to understand their different effect on Arthrospira growth based on their cation, anion, and salt constituents.

2.12. Arthrospira Total Biomass Collection. For collecting the total biomass of the Arthrospira, filtration was performed using sponge covered with gauze.

2.13. Biomass Drying. The Arthrospira wet biomass was dried under aseptic conditions by passing sterile air over the Arthrospira biomass in a sterile microbial cultivation cabinet.

\section{Results and Discussions}

During our testing of media compositions using Chlorella and Arthrospira (both isolated by methods other than media enrichment) in one flask alone or plus a mixture of other unidentified algae (data not shown), we observed that a high amount of $\mathrm{Na}_{2} \mathrm{CO}_{3}(2 \% \mathrm{w} / \mathrm{v})$ enables Arthrospira and Chlorella to flourish but inhibits growth of other algae (Tables 1-3). Given that Arthrospira can grow under auxotrophic condition, we used the peptone/yeast extract and tap water instead of the trace elements mixture. We have selected the components of our new medium from both George's and Zarrouk's media. George's medium is a common medium for algae cultivation. George's medium contains peptone and the tap water in its gradients. The constituents which are used for Zarrouk's medium have been selected based on being a selective medium for the Arthrospira. By accident, we used a double concentration ( $2 \mathrm{x})$ of A-St medium. The $2 \mathrm{x}$ medium upon its used found to be able to cure all the Chlorella. For that we developed a two-step strategy: first using $2 \mathrm{x}$ medium to eradicate Chlorella and then diluting the $2 \mathrm{x}$ medium to $1.5 \mathrm{x}$ so that Arthrospira can flourish again (Tables 1-3). We used a light microscope to evaluate the process and showed that after 2 days of cultivation Chlorella was completely eradicated. Moreover, Arthrospira survived in 2x of our medium without the yeast extract/peptone mixture. This initiated the idea to establish an in fermentor purification for Arthrospira heavily contaminated by Chlorella (10 Arthrospira: 90 Chlorella) (Figures 1(a), 1(b), 1(c), 1(d), and 1(e)). The cell dry weight (CDW) for Arthrospira in A-St 2x and 1.5x media is plotted on a linear or an exponential scale in Figures 1 and 2. The other parameters have been plotted against time in Figures 2 and 6.

The growth curve of Arthrospira represents a typical growth curve of most microbes. It shows a typical lag, log, and stationary phase (Figure 2). The total yield of Arthrospira biomass as CDW was $0.979 \mathrm{~g} / \mathrm{L}(68.53 \mathrm{~g} / 70 \mathrm{l})$. As shown in Figure 2, the growth of Arthrospira in $2 \mathrm{x}$ medium is very weak even though it is still similar to the microbial growth curve in Figures 2, 3, and 4. The calculated productivity $P=\left(x_{\text {end }}-x_{\text {start }}\right) / t_{\text {end }}-t_{\text {start }}$, where $x_{\text {end }}$ and $x_{\text {start }}$ are the CDW $\mathrm{g} / \mathrm{L}$ at the 0 and end points and $t_{\text {end }}$ and $t_{\text {start }}$ are the times at 0 and end points. For cultivation using the $2 x$ medium, the $P_{1}=0.00013 \mathrm{~g} / \mathrm{L} / \mathrm{h}$, the calculated specific growth rate $\mu=\left(\ln x_{2}-\ln x_{1}\right) /\left(t_{2}-t_{1}\right) \mu=0.0215 / \mathrm{h}$, and the calculated generation time $g=\ln 2 / \mu, g=32.23 \mathrm{~h}$. By diluting the medium concentration to $1.5 \mathrm{x}$ as in Figures 3 and 4 , the above values have been increased significantly, where $P_{2}=0.00304 \mathrm{~g} / \mathrm{L} / \mathrm{h}, \mu=0.0406 \mathrm{~g} / \mathrm{h}$, and $g=17.068$. The significant increase in the $P_{\text {increase }}$ and $\mu$ and the decrease in $g$ at $1.5 \mathrm{x}$ medium prove that salinity is an essential factor in the 


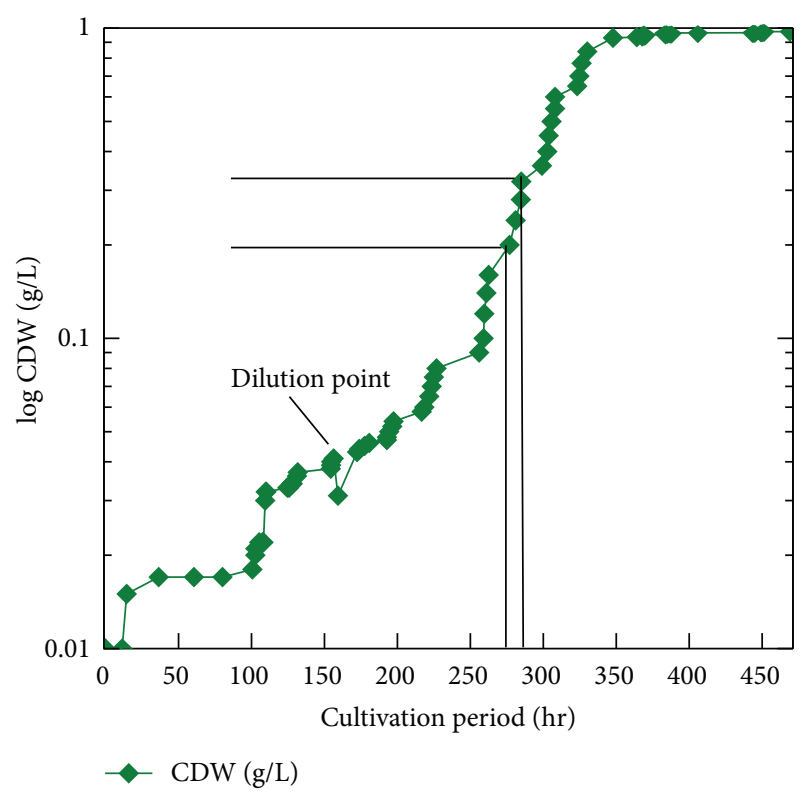

FIgURE 3: Log CDW for the Arthrospira overall cultivation process (A-St $2 \mathrm{x}$ and $1.5 \mathrm{x}$ media).

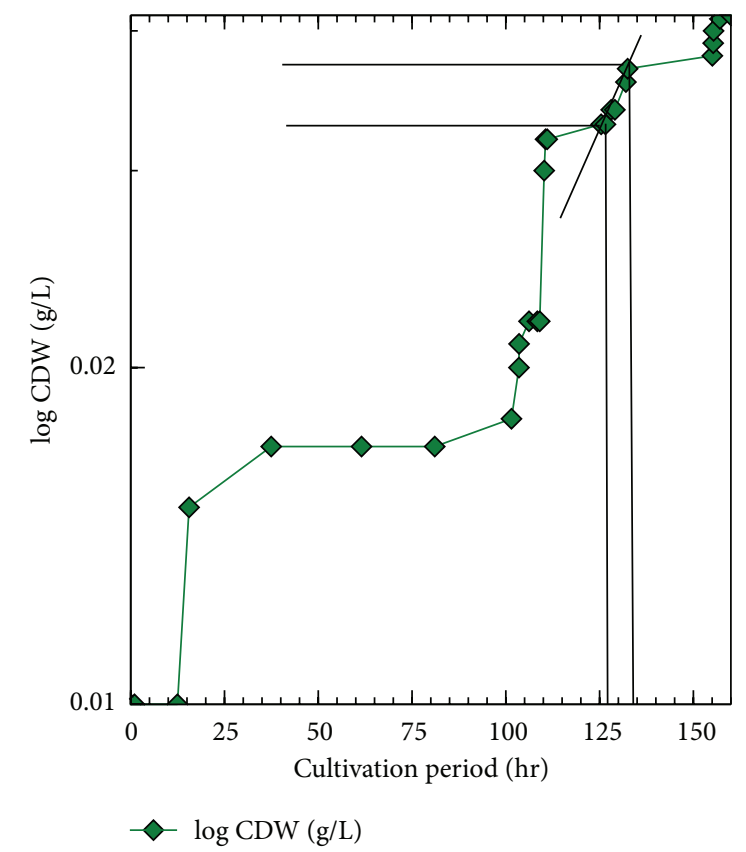

Figure 4: Log CDW for the Arthrospira at A-St 2x medium.

Arthrospira enrichment. The increase in each of theP, $\mu$, and $g$ has been calculated from the following formula:

$$
\% X_{\text {increase }}=\left[\frac{\left(X_{2} * 100\right)}{X_{1}}\right]-100
$$

where $X$ is either $P$ or $\mu$ or $g$.

The calculated $P_{\text {increase }}=2238.4 \%, \mu_{\text {increase }}=88.83 \%$, and $g_{\text {increase }}=-47.04 \%$.

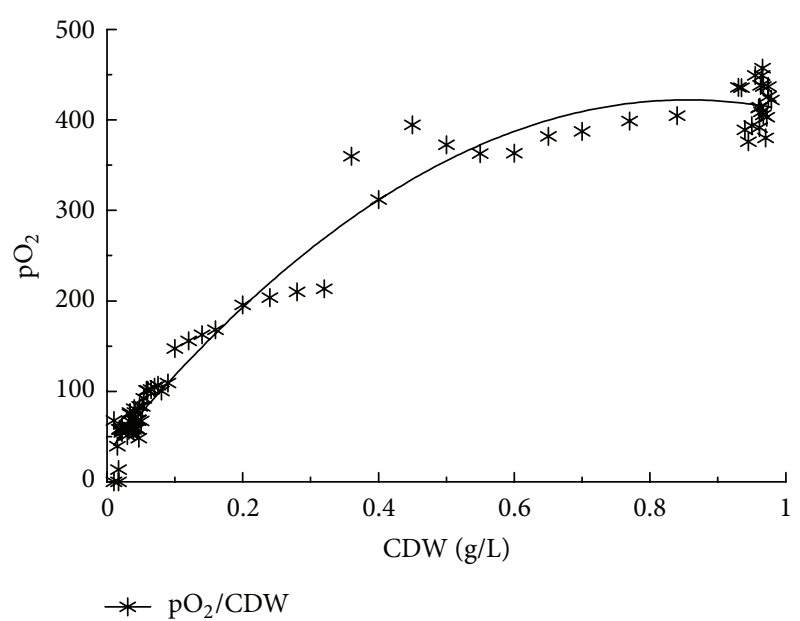

FIgURE 5: Fitted curve of the CDW against $\mathrm{pO}_{2}$.

$\mu$ and $g$, for each of $2 \mathrm{x}$ and $1.5 \mathrm{x}$ have been calculated at nearly the same time from each starting point. We selected the best fitted points in the exponential growth curve at $2 \mathrm{x}$ medium cultivation as in Figure 4 from the following equation: for $2 \mathrm{x}$ cultivation the starting point ( 0 point) is at $0 \mathrm{~h}$ and the end point is at $160 \mathrm{~h}$, while for $1.5 \mathrm{x}$ cultivation the 0 point is at $160 \mathrm{~h}$ and the end point is at $471 \mathrm{~h}$.

The best representative points in both cultivations have been calculated from the following formula:

$$
\begin{gathered}
\text { Point }_{2}=\left(\text { Point }_{1}-\text { Point }_{0(1)}\right) * 2+\left(\text { Point }_{0(2)}-\text { Point }_{1}\right) \\
\text { Point }_{2}=(126-0) * 2+(160-126)=286 \mathrm{~h} .
\end{gathered}
$$

Both of the $2 \mathrm{x}$ and $1.5 \mathrm{x}$ slopes have been selected from the best 4 matching points as in Figures 3 and 4 , where Point ${ }_{0(1)}$ and Point ${ }_{0(2)}$ are the starting points for each cultivation, respectively.

Analysis of the five media used is summarized in Table 1, and their constituents of anion, cation, and $\mathrm{Na}$ salt were calculated as Mol/l. A-St medium at $1 \mathrm{x}$ concentration is similar to Zarrouk's medium, while $2 \mathrm{x}$ medium contains a high amount of salt. A-St 1.5 medium is located in the middle between $\mathrm{x} 2$ and both of A-St $\mathrm{x} 1$ and Zarrouk's medium, and it gave the best result. The hardness of each medium has been calculated from the following formula:

$$
\begin{gathered}
\frac{\mathrm{M} \mathrm{CaCO}_{3}}{\mathrm{M} \mathrm{Ca}}=\frac{100.1}{40.1}=2.5 \\
\frac{\mathrm{M} \mathrm{CaCO}_{3}}{\mathrm{M} \mathrm{Mg}}=\frac{100.1}{24.3}=4.1 \\
{\left[\mathrm{CaCO}_{3}\right]=2.5\left[\mathrm{Ca}^{+2}\right]+4.1\left[\mathrm{Mg}^{2+}\right] .}
\end{gathered}
$$

The different media used, except George's medium, are very hard (Table 2). The increase in the $\mathrm{Ca}$ and $\mathrm{Mg}$ ions leads to an increase in the media total hardness. There is a reverse relationship between the \% of Chlorella and Arthrospira in different $\mathrm{Na}$ salt concentrations where Chlorella decreases 


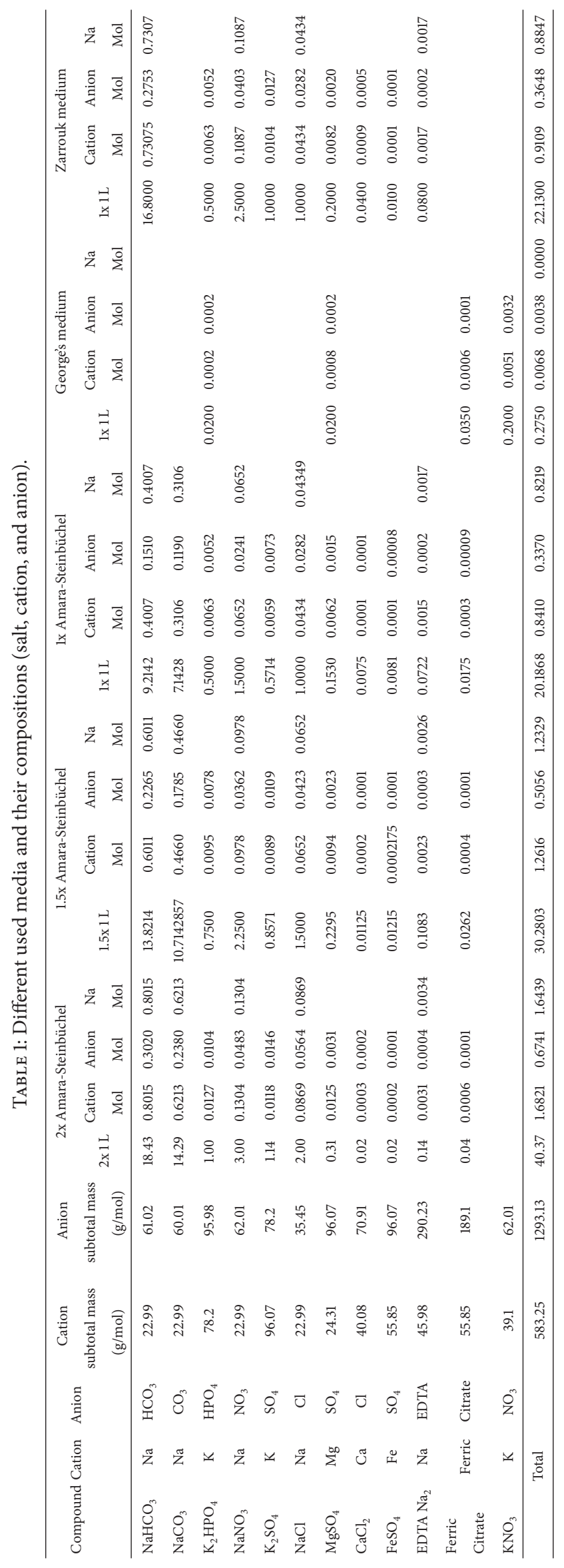


TABLE 2: Water hardness of the different used media.

\begin{tabular}{|c|c|c|c|c|c|}
\hline & A-St $2 x$ & A-St $1.5 x$ & A-St $1 \mathrm{x}$ & George's & Zarrouk's \\
\hline $\mathrm{MgSO}_{4}$ & 0.0125 & 0.0094 & 0.0062 & 0.0008 & 0.0082 \\
\hline $\mathrm{CaCl}_{2}$ & 0.0003 & 0.0002 & 00001 & - & 0.0009 \\
\hline Equivalent $\mathrm{mg} \mathrm{L}^{-1}$ or ppm of $\mathrm{CaCO}_{3}$ & $1.28 e^{+3}$ & 957 & 628 & - & 907 \\
\hline French degree & 128 & 95.7 & 62.8 & - & 90.7 \\
\hline German degree & 71.4 & 53.6 & 35.2 & - & 50.8 \\
\hline English degree & 89.3 & 67.0 & 43.9 & - & 63.8 \\
\hline
\end{tabular}

\begin{tabular}{lllll}
\hline Water hardness & Very hard water & Very hard water & Very hard water & Very hard water
\end{tabular}

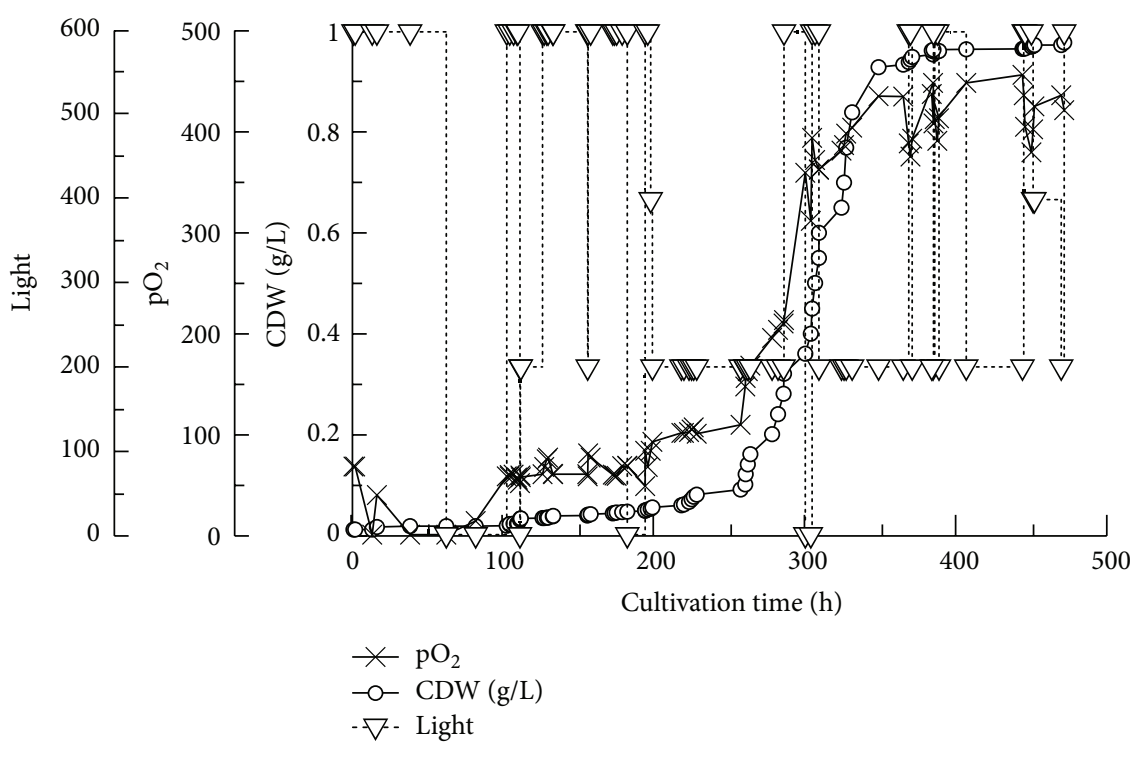

FIgURE 6: The effect of the light in both $\mathrm{pO}_{2}$ and $\mathrm{CDW} \mathrm{g} / \mathrm{L}$.

with increasing new salt concentration and vice versa in the case of Arthrospira (Table 3). The relationship between $\mathrm{pO}_{2}$ and the Arthrospira CDW is linear as shown in Figures 2 and 5; that is, an increase in the Arthrospira CDW causes an increase in $\mathrm{pO}_{2}$. Different light intensities, including 0, 200, 400, and 600, have been used as shown in Figure 6, and the $\mathrm{pO}_{2}$ is more sensitive for monitoring the effect of light in the cultivation process. In the lag and log phase, the change in light intensity is not clearly detected except at a few points (e.g., at $300 \mathrm{~h}$ ). This is because in the lag phase cell growth and division are very slow and in the log phase they are very high. The change could not be detected clearly in both growth phases; however, in the stationary phase, where the growth becomes more stable and constant, the effect has been clearly observed and showed that the decrease in light intensity led to a decrease in growth as well as in the amount of the released $\mathrm{pO}_{2}$ as in Figure 6 .

Arthrospira can exist in harsh conditions, and it can even be used in bioremediation of toxic elements such as lead and other toxic elements and compounds [31,32]. Heterotrophic metabolism is faster than autotrophic [33]. Aiming to eradicate Chlorella, we used stresses which included high levels of alkalinity, salinity, and autotrophic growth. Arthrospira proved to be able to survive in these conditions while Chlorella did not. In the photobioreactor, we used autotrophic conditions first to put Arthrospira and Chlorella in maximum expected stress (we added yeast extract/peptone mixture after diluting the medium to $1.5 \mathrm{x}$ ). Temperature, which can affect $\mathrm{pO}_{2}$ and $\mathrm{pH}$, was set to $30^{\circ} \mathrm{C}$. After $160 \mathrm{~h}$ of these harsh conditions, the $2 \mathrm{x}$ A-St medium was then diluted to $1.5 \mathrm{x}$, and the Arthrospira growth started to show an increase in its biomass as shown in Figures 1(b) and 1(c).

We stopped the process after about $471 \mathrm{~h}$ after the growth rate had become saturated. The increase in the biomass is relatively equal to the increase in the $\mathrm{pO}_{2}$ (\% of saturation) which is logical, while the elevation of $\mathrm{O}_{2}$ is an indicator of the cell growth and multiplication. $\mathrm{pO}_{2}$ and $\mathrm{pH}$ are negatively affected by temperature. The mixing process leads to an increase in the fermentation process temperature. However, the range of the change in each of the $\mathrm{pH}$ and $\mathrm{O}_{2}$ is narrow. The sudden change in $\mathrm{pO}_{2}$ amount means that there is a direct effect on the Arthrospira growth as in Figures 2, 3, and 4 . The $\mu, P$, and $g$ parameters of the growth before and after the medium dilution prove that $1.5 \mathrm{x} \mathrm{A}$-St medium is better for growing Arthrospira than 2x A-St medium. This is another proof about the role of salinity level in the growth of cyanobacteria. Therefore, the analysis of the different media which have been used according to their anion, cation, and salinity is shown in Table 1 . According to the data in Table 3 as well as that in Tables 1 and 2, salinity is the major factor 
TABLE 3: The \% of the cells for both Chlorella and Arthrospira in different media.

\begin{tabular}{lccc}
\hline Media names & $\mathrm{Na}$ & Chlorella & Arthrospira \\
\hline George's & 0 & 99 & 1 \\
A-St 1x & 0.8129 & 92 & 8 \\
Zarrouk's & 0.8847 & 90 & 10 \\
A-St 1.5x & 1.2329 & 30 & 70 \\
A-St 2x & 1.6439 & 0 & 100 \\
\hline
\end{tabular}

which leads to the eradication of the Chlorella. On the other hand, Arthrospira proves to be a powerful strain that could resist different kind of stresses, especially those used in our study.

This study did not investigate conditions for Arthrospira overproduction or its active constituents' analysis, which should be covered in future studies. However, it clearly proves the role of salinity in its growth, in the enrichment, and in the inhibition of other algal species. Other Arthrospira should be tested as case-by-case study because there is great variability in the genotype and the stage of the growth cycle (as well as many other factors) as reported by Ruengjitchatchawalya et al. (2002) [34]. By mimicking its natural habitat and using the photobioreactor within fermentor partial randomization for its cultivation conditions, we gain a better understanding for Arthrospira growth conditions.

\section{Conclusion}

In conclusion, salinity was the major factor which leads to the dominance of Arthrospira rather than the alkalinity. Purifying Arthrospira from contaminated algae to reach a pharmaceutical grade using $2 \mathrm{x} / 1.5 \mathrm{x}$ A-St media is a step to improve the Arthrospira quality. Tap water and yeast extract/peptone mixture can substitute the trace elements in the Arthrospira commercial production. The temperature could change the amount of $\mathrm{pO}_{2}$ and the $\mathrm{pH}$ value either by direct effect or by inducing chemical or physical changes. Arthrospira can sense any change in its environment. Arthrospira has proved to be more environmentally adapted to stress than Chlorella. In this study, we succeeded in developing a medium and cultivation conditions enabling the enrichment of the Arthrospira and the inhibition of the other algal species based on salinity. Using the photobioreactor and conducting a complete cultivation process (lag-log-stationary phases) have been proved to be the most efficient and quickest ways to understand the different responses of Arthrospira to the different modifications during its cultivation conditions. This study will open the way to produce a pure culture of Arthrospira. Most methods used nowadays do not guarantee pure Arthrospira production which affects its product quality. Our new method is not expensive, reliable, and cost effective. The medium which was taken from the fermentor during the dilution step can be diluted and reused. In fermentor Arthrospira can be produced without any algal or cyanobacteria contaminant. This will enable the production of pure Arthrospira and enables the purification of a previously produced contaminated Arthrospira (e.g., obtained from open ponds).

\section{Conflict of Interests}

The authors declare that there is no conflict of interests

\section{Acknowledgment}

The authors acknowledge Dipl. Eng. Herbert Ahlers for some technical support during this work. They also acknowledge the grant provided from the DAAD which supports part of this study.

\section{References}

[1] O. Ciferri, "Spirulina, the edible microorganism," Microbiological Reviews, vol. 47, no. 4, pp. 551-578, 1983.

[2] E. Kebede, "Response of Spirulina platensis (=Arthrospira fusiformis) from Lake Chitu, Ethiopia, to salinity stress from sodium salts," Journal of Applied Phycology, vol. 9, no. 6, pp. 551$558,1997$.

[3] P. J. F. Turpin, "Spirulina oscillarioide," in Dictionnaire des Sciences Naturelles, vol. 50, pp. 309-310, DeLevrault, Paris, France, 1827.

[4] G.-G. Choi, C.-Y. Ahn, and H.-M. Oh, "Phylogenetic relationships of Arthrospira strainsinferred from16SrRNA geneand cpcBA-IGS sequences," Algae, vol. 27, no. 2, pp. 75-82, 2012.

[5] F. Rich, "Notes on Arthrospira platetnsis," Rev Algol, vol. 6, pp. 75-79, 1931.

[6] P. Dangeard, "Sur une algue bleue alimentaire pour l'homme: Arthrospira platensis (Nordst.)," Gomont. Actes Soc. Linn. Boreaux Extr. Procés-Verbaux, vol. 91, pp. 39-41, 1940.

[7] G. Chamorro, M. Salazar, K. G. de Lima Araújo, C. P. dos Santos, G. Ceballos, and L. F. Castillo, "Update on the pharmacology of Spirulina (Arthrospira), an unconventional food," Archivos Latinoamericanos de Nutricion, vol. 52, no. 3, pp. 232-240, 2002.

[8] A. Richmond, "Large scale microalgal culture and applications," in Progressin Phycological Research, vol. 7, Biopress, Bristol, UK, 1990.

[9] I. Avila-Leon, M. Chuei Matsudo, S. Sato, and J. C. M. De Carvalho, "Arthrospira platensis biomass with high protein content cultivated in continuous process using urea as nitrogen source," Journal of Applied Microbiology, vol. 112, pp. 1086-1094, 2012.

[10] H. Shimamatsu, "Mass production of Spirulina, an edible microalga," Hydrobiologia, vol. 512, pp. 39-44, 2004.

[11] C. Zarrouk, Contribution a l'etude d'une cyanophycee. Influence de divers facteurs physiques et chimiques sur la croissance et la photosynthese de Spirulina maxima (Setch. et Gardner). Geitler [Ph.D. thesis], University of Paris, Paris, France, 1966.

[12] A. Iltis, "Tolerance de salinite de Spirulina platensis (Gom.). Geitl., (Cyanophyta). dans les mares natronees du Kanem 
(Tchad)," Cahiers ORSTOM: Série Hydrobiologie, vol. 2, pp. 119125, 1968.

[13] E. A. Davis, "Growth of algae in mass culture: plastic and glass tubing," in Algal Culture: From LaboraTory To Pilot Plant, J. S. Burlew, Ed., pp. 113-153, Carnegie Institution of Washington, Washington, DC, USA, 1953.

[14] Y.-K. Lee and C.-S. Low, "Effect of photobioreactor inclination on the biomass productivity of an outdoor algal culture," Biotechnology and Bioengineering, vol. 38, no. 9, pp. 995-1000, 1991.

[15] O. Pulz and P. Kretschmer, "Perspectives of phototrophic microorganisms in environment protection and ecology," Acta Biotechnologica, vol. 12, no. 6, pp. 517-520, 1992.

[16] T. Hai, H. Ahlers, V. Gorenflo, and A. Steinbüchel, "Axenic cultivation of anoxygenic phototrophic bacteria, cyanobacteria, and microalgae in a new closed tubular glass photobioreactor," Applied Microbiology and Biotechnology, vol. 53, no. 4, pp. 383$389,2000$.

[17] S. Oncel and F. V. Sukan, "Comparison of two different pneumatically mixed column photobioreactors for the cultivation of Artrospira platensis (Spirulina platensis)," Bioresource Technology, vol. 99, no. 11, pp. 4755-4760, 2008.

[18] M. C. Matsudo, R. P. Bezerra, S. Sato, A. Converti, and J. C. M. de Carvalho, "Photosynthetic efficiency and rate of $\mathrm{CO}_{2}$ assimilation by Arthrospira (Spirulina) platensis continuously cultivated in a tubular photobioreactor," Biotechnology Journal, vol. 7, pp. 1412-1417, 2012.

[19] D. L. Narasimha, G. S. Venkataraman, S. K. Duggal, and B. O. Eggum, "Nutritional quality of the blue-green alga Spirulina platensis Geitler," Journal of the Science of Food and Agriculture, vol. 33, no. 5, pp. 456-460, 1982.

[20] A. Belay, T. Kato, and Y. Ota, "Spirulina (Arthrospira): potential application as an animal feed supplement," Journal of Applied Phycology, vol. 8, no. 4-5, pp. 303-311, 1996.

[21] J. J. Ortega-Calvo, C. Mazuelos, B. Hermosin, and C. SaizJimenez, "Chemical composition of Spirulina and eukaryotic algae food products marketed in Spain," Journal of Applied Phycology, vol. 5, no. 4, pp. 425-435, 1993.

[22] T. Hirata, M. Tanaka, M. Ooike, T. Tsunomura, and M. Sakaguchi, "Antioxidant activities of phycocyanobilin prepared from Spirulina platensis," Journal of Applied Phycology, vol. 12, no. 3-5, pp. 435-439, 2000.

[23] T. Kato, "Blue pigment from Spirulina," New Food Industry, vol. 29, pp. 17-21, 1994.

[24] A. T. Kursar and S. R. Alberte, "Photosyntheticunit organization in a red algae," Plant Physiology, vol. 72, pp. 409-414, 1983.

[25] R. Rodríguez-Sánchez, R. Ortiz- Butrón, V. Blas-Valdivia, A. Hernández-García, and E. Cano-Europa, "Phycobiliproteins or C-phycocyanin of Arthrospira (Spirulina) maxima protect against $\mathrm{HgCl}(2)$-caused oxidative stress and renal damage," Food Chemistry, vol. 135, no. 4, pp. 2359-2365, 2012.

[26] M. Sharaf, A. Amara, A. Aboul-Enein et al., "Molecular authentication and characterization of the antiherpetic activity of the cyanobacterium Arthrospira fusiformis," Pharmazie, vol. 65, no. 2, pp. 132-136, 2010.

[27] T. Hayashi, K. Hayashi, M. Maeda, and I. Kojima, "Calcium spirulan, an inhibitor of enveloped virus replication, from a blue-green alga Spirulina platensis," Journal of Natural Products, vol. 59, no. 1, pp. 83-87, 1996.

[28] H. Gong, Y. Tang, J. Wang, X. Wen, L. Zhang, and C. Lu, "Characterization of photosystem II in salt-stressed cyanobacterial
Spirulina platensis cells," Biochimica et Biophysica Acta, vol. 1777, no. 6, pp. 488-495, 2008.

[29] C. Lu and J. Zhang, "Role of light in the response of PSII photochemistry to salt stress in the cyanobacterium Spirulina platensis," Journal of Experimental Botany, vol. 51, no. 346, pp. 911-917, 2000.

[30] R. M. Atlas and L. C. Parks, Handbook of Microbiological Media, CRC. Press, Boca Raton, Fla, USA, 2nd edition, 1997.

[31] H. Chen and S.-S. Pan, "Bioremediation potential of spirulina: toxicity and biosorption studies of lead," Journal of Zhejiang University, vol. 6, no. 3, pp. 171-174, 2005.

[32] A. V. Kotinsky, L. A. Chernukhina, G. V. Donchenko et al., "Effect of iodine and cobalt salts on biologically active substances content in spirulina biomass," Ukrain'skyi Biokhimichnyi Zhurnal, vol. 76, no. 2, pp. 112-116, 2004.

[33] A. Lodi, L. Binaghi, C. Solisio, A. Converti, and M. Del Borghi, "Nitrate and phosphate removal by Spirulina platensis," Journal of Industrial Microbiology and Biotechnology, vol. 30, no. 11, pp. 656-660, 2003.

[34] M. Ruengjitchatchawalya, N. Chirasuwan, R. Chaiklahan, B. Bunnag, M. Tanticharoen, and P. Deshnium, "Photosynthetic characterization of a mutant of Spirulina platensis," Journal of Applied Phycology, vol. 14, no. 2, pp. 71-76, 2002. 

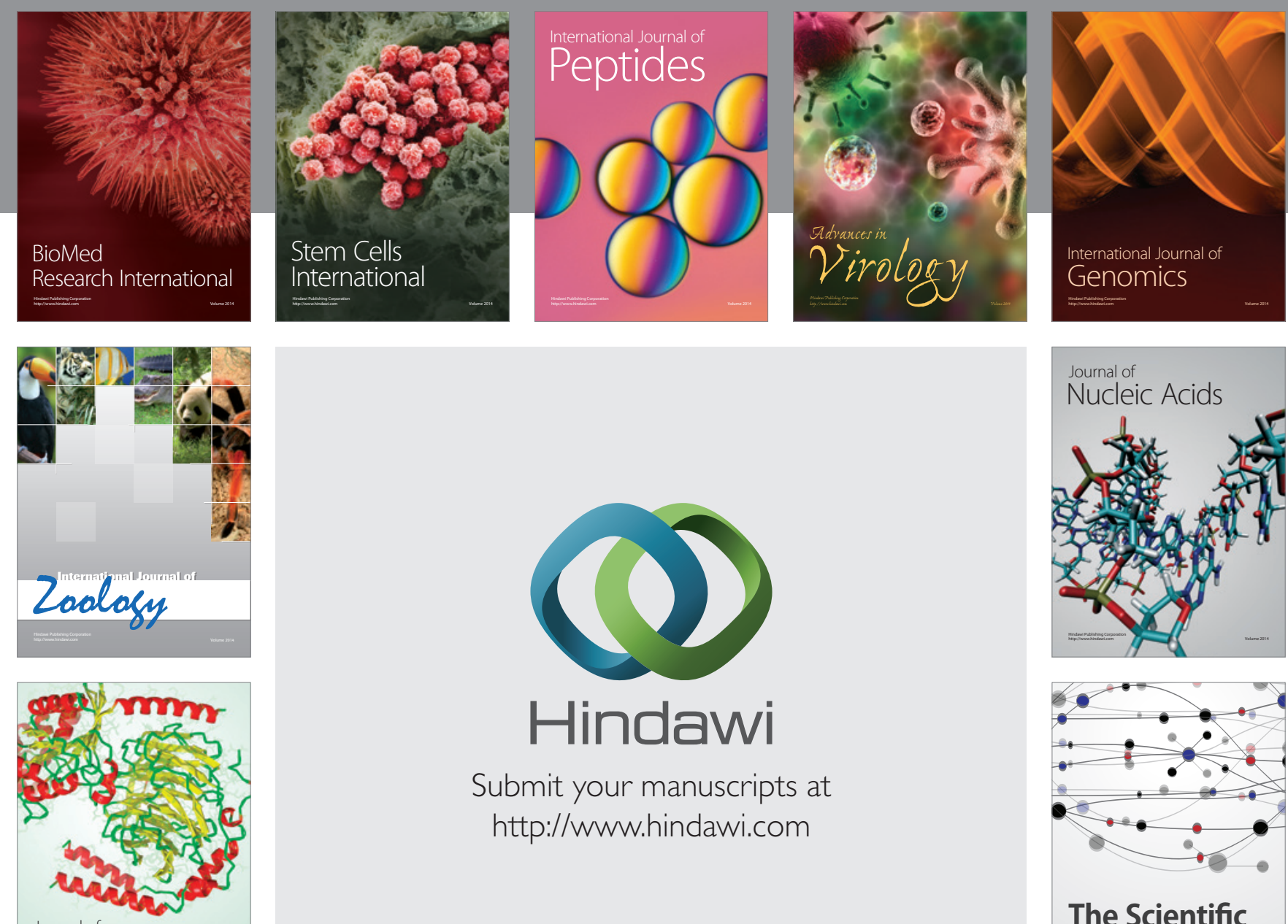

Submit your manuscripts at

http://www.hindawi.com

Journal of
Signal Transduction
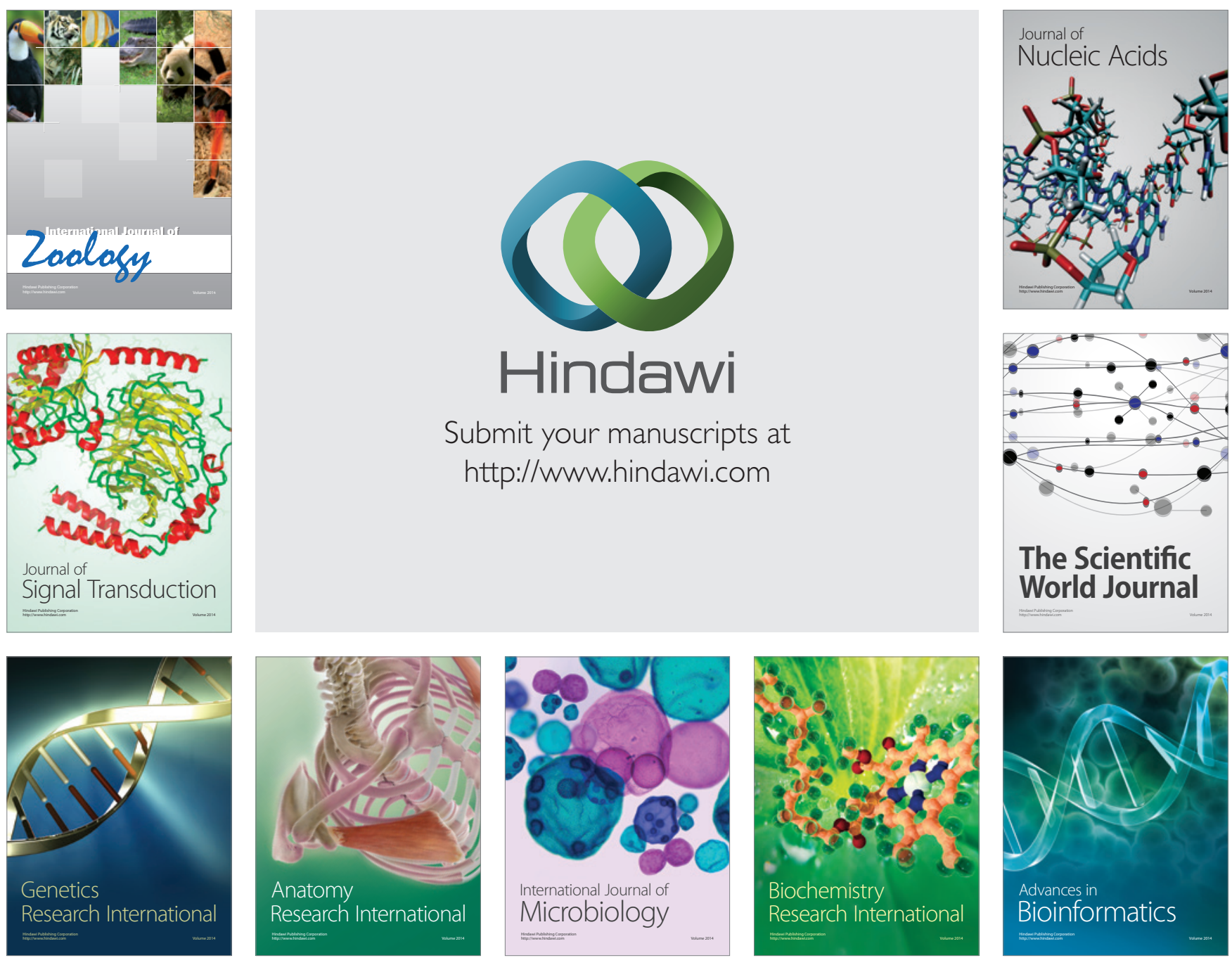

The Scientific World Journal
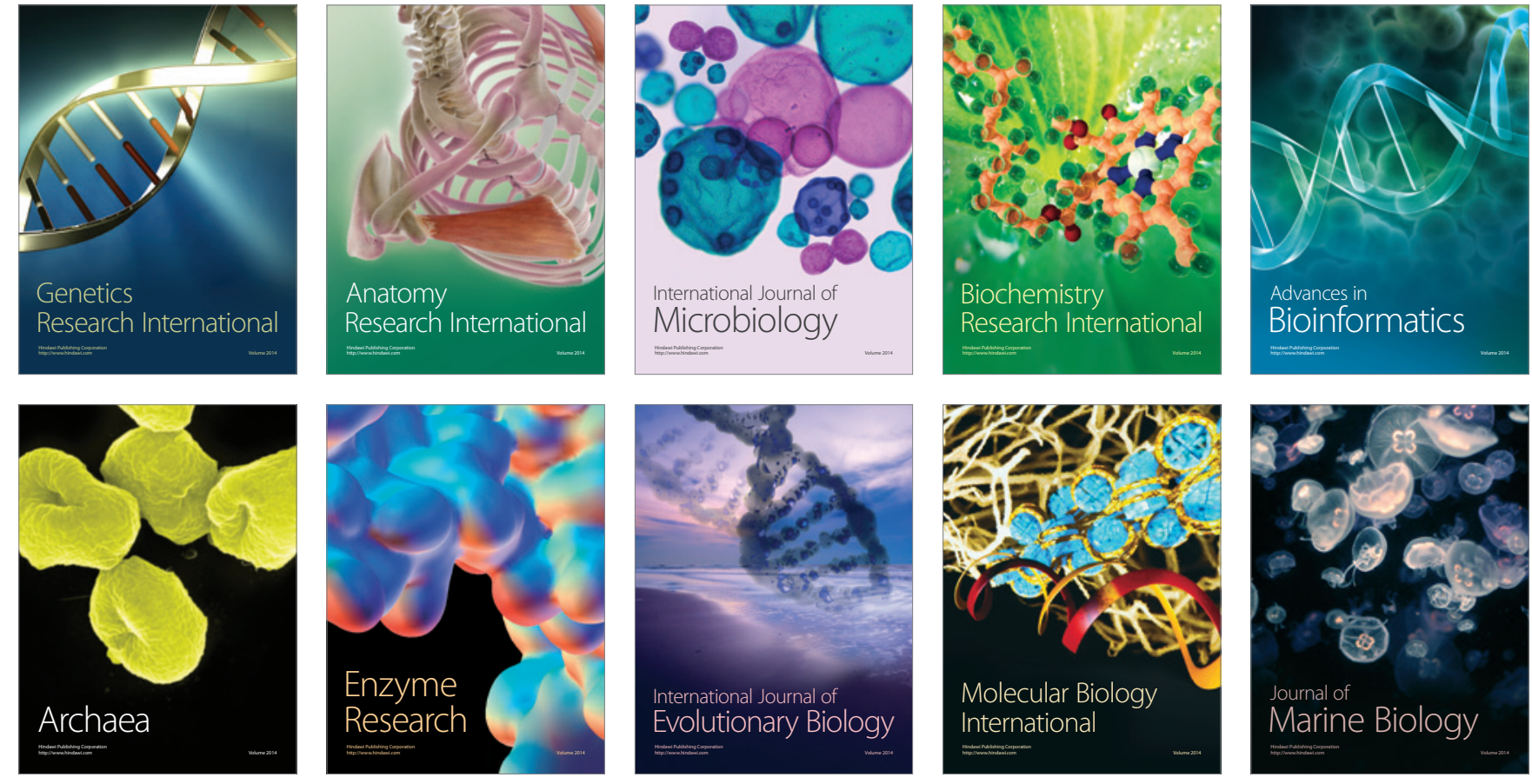